\title{
RESONANT FREQUENCY OF HIGHER ORDER MODES FOR CIRCULAR MICROSTRIP ANTENNAS
}

\author{
Rajanish and T. S. Vedavathy \\ Department of Electrical Communication Engineering \\ Indian Institute of Science, Bangalore, India.
}

\begin{abstract}
A modified expression for calculating the resonant frequency for higher order modes of circular microstrip antenna is presented in this paper. It is found that by using the cavity model analysis to calculate the frequency for higher order modes, the frequency difference between the theoretical and measured values increases as the order of the mode increases. This discrepancy is eliminated by generalizing the expression for resonant frequency in cavity model to include the mode order and thus modifying the effective capacitance used in the analysis. The theoretical results obtained are in excellent agreement with the experimental values.
\end{abstract}

\section{INTRODUCTION}

The use of higher order modes has found profound usefulness in the applications such as GPS, mobile communications, etc. Various analyses have been carried out to determine the resonant frequency of the microstrip antennas of which cavity model is the simplest. But, it is found in [1] and [2] that the same analysis which is used to calculate the resonant frequency of the patch in the dominant mode is applied to the case of higher order modes also. This leads to a large difference between theoretical and experimental values. In this paper, an effective capacitance analysis is formulated, which takes care of the mode variation effect on the resonant frequency. Here, the patch antennas of circular geometry, i.e., disk and annular ring are considered.

\section{ANALYSIS}

\section{A. Disk Antenna}

The resonant frequency of microstrip antenna is governed by the accuracy of the capacitance of the patch resonator. It was discussed in [3] that the experiments showed that the resonant frequency calculated using zero-order capacitance was always higher than the measured data and thus a better approximation for the capacitance was developed [3] as,

$$
C^{(l)}=C^{(0 j}(1+\Delta) \quad \cdots(1)
$$

The modified resonant frequency is then given as,

$$
f^{(1)}=\frac{1}{2 \pi \sqrt{L^{(1)} C^{(1)}(1+\Delta)}}
$$

where, for small $\mathrm{h} / \mathrm{a}$,

$$
\Delta=\frac{2 h}{\pi a \varepsilon,}\left(\ln \frac{\pi a}{2 h}+1.7726\right)
$$

and

$$
L^{(1)}=\frac{\mu h}{\pi X_{n m}^{2}}
$$


where, $a$ is the radius of the disk, $h$ is the height of the substrate and $x_{\mathrm{rm}}=k_{n m}$ a) are the solutions of the characteristic equation of the circular disc, derived by applying magnetic wall model (cavity model) :

$$
J_{n}^{\prime}\left(X_{n m}\right)=0
$$

Thus, a simple algebraic formula for the first-order capacitance is available when the dielectric substrate is replaced by air. But, it is again observed from the experimental results that these formulas provide comparable results only for the dominant mode. Using the same formula for calculating the resonant frequency of higher order modes, gives a considerable difference between theoretical and measured values. Hence, the capacitance also needs to incorporate the mode variables, ' $n$ ' and ' $m$ ' to provide a better accuracy. The logarithmic term is modified for a better approximation of capacitance for the higher order modes as,

$$
\Delta=\frac{2 h}{\pi a \varepsilon_{r}}\left(\ln \frac{\pi a}{2 h \alpha^{2}} \cdot \beta^{3}+1.7726\right) \cdots(6)
$$

Now, the general formula of capacitance for any mode is

$C^{(1)}=C^{(0)}\left[1+\frac{2 h}{\pi a \varepsilon_{r}}\left(\ln \frac{\pi a}{2 h \alpha^{2}} \cdot \beta^{3}+1.7726\right)\right]$

where, $\mathrm{n}=$ order of the Bessel function $\mathrm{m}=\mathrm{m}^{\text {th }}$ zero of the function $J_{n}^{\prime}(\mathrm{ka})$

$\alpha=\left\{\begin{array}{cc}\mathrm{n}, & \mathrm{n} \geq 1 \\ 1, & \mathrm{n}=0\end{array}\right.$
$\beta=\mathrm{m} \quad \forall \mathrm{m}$
Table 1. Comparison of resonant frequencies

\begin{tabular}{|c|c|c|c|c|c|}
\hline $\begin{array}{c}\text { Method } \\
\rightarrow \\
\text { Mode } \\
\downarrow\end{array}$ & $\begin{array}{c}\text { Exper. } \\
\text { Value } \\
{[2]} \\
(\mathrm{GHz})\end{array}$ & $\begin{array}{c}\text { Theor. } \\
\text { Value } \\
{[2]} \\
(\mathrm{GHz})\end{array}$ & $\begin{array}{c}\% \\
\text { Error }\end{array}$ & $\begin{array}{c}\text { Proposed } \\
\text { Method } \\
(\mathrm{GHz})\end{array}$ & $\begin{array}{c}\% \\
\text { Error }\end{array}$ \\
\hline $\mathrm{TM}_{11}$ & 1.128 & 1.127 & .11 & 1.127 & .11 \\
\hline $\mathrm{TM}_{21}$ & 1.879 & 1.869 & .53 & 1.880 & .06 \\
\hline $\mathrm{TM}_{31}$ & 2.596 & 2.571 & .96 & 2.595 & .05 \\
\hline
\end{tabular}
of circular disk antennas with [2]

$\mathrm{a}=5.0 \mathrm{~cm}, \mathrm{~h}=0.159 \mathrm{~cm}, \mathrm{~d}=4.75 \mathrm{~cm}, \varepsilon_{\mathrm{r}}=.32$

Table 2. Comparison of resonant frequencies of circular disk antennas with [4]

\begin{tabular}{cccc} 
Method $\rightarrow$ & $\begin{array}{c}\text { Experimental } \\
\text { Value [4] } \\
(\mathrm{MHz})\end{array}$ & $\begin{array}{c}\text { Proposed } \\
\text { Method } \\
(\mathrm{MHz})\end{array}$ & $\begin{array}{c}\% \\
\text { Error }\end{array}$ \\
\hline $\mathrm{TM}_{11}$ & 794 & 792 & .27 \\
$\mathrm{TM}_{21}$ & 1324 & 1318 & .43
\end{tabular}

$\mathrm{a}=6.75 \mathrm{~cm}, \mathrm{~h}=0.15 \mathrm{~cm}, \mathrm{~d}=4.75 \mathrm{~cm}, \varepsilon_{\mathrm{r}}=2.62$

\section{B. Annular Ring Antenna}

The modified first order capacitance is applied to the annular ring antenna by considering the inner and outer radiating circular edges as edges of smaller and larger disk, respectively, giving modified inner edge of annular ring ' $a$ ' and outer edge ' $b$ ' as

$a_{e f f}=a\left[1-\frac{2 h}{\pi a \varepsilon_{e f f}}\left(\ln \frac{\pi a}{2 h \alpha^{2}} \cdot \beta^{3}+1.7726\right)\right]^{1 / 2}-(8)$

$b_{e f f}=b\left[1+\frac{2 h}{\pi b \varepsilon_{e f f}}\left(\ln \frac{\pi b}{2 h \alpha^{2}} \cdot \beta^{3}+1.7726\right)\right]^{1,2}--(9)$

The resonant frequency of the antenna is then evaluated from

$$
f_{r}=\left(k_{n m} c\right) /\left(2 \pi \sqrt{ } \varepsilon_{e f f}\right)
$$


where, $\mathrm{c}=$ velocity of light in free space $=3 \times 10^{8} \mathrm{~m} / \mathrm{s}$ and $k_{n m} \equiv$ roots of the characteristic equation for an annular ring resonator using magnetic wall model is given by

$$
J_{n}^{\prime}(k a) Y_{n}^{\prime}(k b)-J_{n}^{\prime}(k b) Y_{n}^{\prime}(k a)=0 \quad-(11)
$$

Formula for $\varepsilon_{e f f}$ as given by [1].

Table 3. Comparison of resonant frequencies of annular ring antennas with [2]

\begin{tabular}{|c|c|c|c|c|c|}
\hline $\begin{array}{c}\text { Method } \\
\rightarrow \\
\text { Mode } \\
\downarrow\end{array}$ & $\begin{array}{c}\text { Exper. } \\
\text { Value } \\
{[2]} \\
(\mathrm{MHz})\end{array}$ & $\begin{array}{c}\text { Theor. } \\
\text { Value } \\
{[2]} \\
(\mathrm{MHz})\end{array}$ & $\begin{array}{c}\% \\
\text { Error }\end{array}$ & $\begin{array}{l}\text { Proposed } \\
\text { Method } \\
(\mathrm{MHz})\end{array}$ & $\begin{array}{c}\% \\
\text { Error }\end{array}$ \\
\hline $\mathrm{TM}_{11}$ & 626 & 622 & .64 & 622 & .64 \\
\hline $\mathrm{TM}_{21}$ & 1229 & 1220 & .73 & 1228 & .08 \\
\hline $\mathrm{TM}_{3 !}$ & 1800 & 1793 & .39 & 1801 & .06 \\
\hline $\mathrm{TM}_{12}$ & 2757 & 2820 & 2.29 & 2764 & .25 \\
\hline
\end{tabular}

$\mathrm{a}=3.5 \mathrm{~cm}, \mathrm{~b}=7.0 \mathrm{~cm}, \mathrm{~h}=0.159 \mathrm{~cm}, \mathrm{~d}=3.6 \mathrm{~cm}$, $\varepsilon_{\mathrm{T}}=2.32$

\section{RESULTS AND DISCUSSION}

Resonant frequency of circular and annular ring antennas is calculated using the modified expressions and is compared with the experimental results reported in the literature by Lee and Dahele [2] and Lo et. al [4] in Tables 1,2 and 3 . Error percentage is calculated to show the close agreement of proposed method with the experimental values. In Table 1 , the resonant frequency of the circular disk antenna is compared with those obtained by simple cavity model. We can observe that for the higher order modes, $\mathrm{TM}_{21}$ and $\mathrm{TM}_{31}$, the error percentage against experimental values published in [2] is very small as compared to the theoretical values obtained by the same. The magnitude of the error is of the order of $.05 \%$ $.06 \%$ which reflects that the higher order mode antennas can also be designed with most accuracy and less trimming of patch to obtain the desired performance. This in turn saves the cost of manufacturing. To establish the proposed theory, the computation of the resonant frequency is also carried out for the experiments published in [4]. It is shown in Table 3 that by modifying the annular ring capacitance as per the same guidelines for disk we get an improved theory for the resonant frequency of the annular ring antennas too. We see a large improvement over the conventional theoretical analysis, thus improving the accuracy as required by the designers.

\section{CONCLUSION}

Modified expression for the calculation of resonant frequency of higher order modes excited resonant microstrip. patch antennas gives best accuracy as compared to the theoretical results found in the literature. The theoretical results are compared with the experimental results obtained by established researchers in this field. Moreover, it gives a generalized formula for calculating the resonant frequency of patch antennas by cavity model for all modes. Validation of various experimental results with the proposed theory confirms the stand.

\section{ACKNOWLEDGEMENT}

The authors are thankful to Indian Space Research Organization for funding this work. 


\section{REFERENCES}

[1] J. R James and P. S. Hall, "Hand Book of Microstrip Antennas," Vol. I. pp. 171-173, 1989

[2] J. S. Dahele and Kai F. Lee, "Theory and experiment on microstrip antennas with airgaps," IEE Proc. Pt. H, no. 7, pp. 455-460, Dec. 1985.

[3] L. C. Shen, S. A. Long, M. R. Allerding and M. D. Walton, "Resonant frequency of a circular disc. printed circuit antenna," IEEE Trans. $A P$, pp. 595-596, July 1979.

[4] Lo, Y. T., Solomon, D., and Richards, W. F., "Theory and experiment on microstrip antennas," IEEE Trans. Antennas Propagat., vol. 27, pp. 137-145, 1979. 